\title{
Article
}

\section{Artemisinin analogue SM934 ameliorates DSS- induced mouse ulcerative colitis via suppressing neutrophils and macrophages}

\author{
Yu-xi YAN ${ }^{1,2}$, Mei-juan SHAO ${ }^{3}$, Qing $\mathrm{QI}^{1}$, Yan-sheng XU ${ }^{3}$, Xiao-qian YANG ${ }^{1}$, Feng-hua ZHU ${ }^{1}$, Shi-jun $\mathrm{HE}^{1}$, Pei-lan $\mathrm{HE}^{1}$, Chun-lan \\ $\mathrm{FENG}^{1}$, Yan-wei $\mathrm{WU}^{1}$, Heng $\mathrm{LI}^{1,2}$, Wei TANG ${ }^{1,2, *}$, Jian-ping $\mathrm{ZUO}^{1,2,3, *}$ \\ ${ }^{1}$ Laboratory of Immunopharmacology, State Key Laboratory of Drug Research, Shanghai Institute of Materia Medica, Chinese Academy \\ of Sciences, Shanghai 201203, China; ${ }^{2}$ University of Chinese Academy of Sciences, Beijing 100049, China; ${ }^{3}$ Laboratory of Immunology \\ and Virology, Shanghai University of Traditional Chinese Medicine, Shanghai 201203, China
}

\begin{abstract}
Ulcerative colitis (UC) is a chronic, nonspecific inflammatory bowel disease (IBD) characterized by complicated and relapsing inflammation in the gastrointestinal tract. SM934 is a water-soluble artemisinin analogue that shows anti-inflammatory and immunoregulatory effects. In this study, we investigated the effects of SM934 on UC both in vivo and in vitro. A mouse model of colitis was established in mice by oral administration of $5 \%$ dextran sulfate sodium (DSS). SM934 (3, $10 \mathrm{mg} / \mathrm{kg}$ per day, ig) was administered to the mice for 10 days. After the mice were sacrificed, colons, spleens and mesenteric lymph nodes (MLNs) were collected for analyses. SM934 administration restored DSS-induced body weight loss, colon shortening, injury and inflammation scores. Furthermore, SM934 administration significantly decreased the disease activity index (DAl), histopathological scores, and myeloperoxidase (MPO) activities in colonic tissues. Moreover, SM934 administration dose-dependently decreased the mRNA and protein levels of DSS-induced proinflammatory cytokines (IL-1 $\beta$, IL- 6 and TNF- $\alpha$ ), and the percentage of macrophages and neutrophils in colon tissues. The effects of SM934 on LPS-stimulated RAW 264.7 cells and THP-1-derived macrophages were examined in vitro. Treatment with SM934 (0.8, $8,80 \mu \mathrm{mol} / \mathrm{L}$ ) dose-dependently decreased the production of pro-inflammatory mediators in LPS-stimulated RAW 264.7 cells and THP-1-derived macrophages via inhibiting activation of the NF-kB signaling. Our results reveal the protective effects of SM934 on DSS-induced colitis can be attributed to its suppressing effects on neutrophils and macrophages and its inhibitory role in the NF-KB signaling, suggests that SM934 might be a potential effective drug for ulcerative colitis.
\end{abstract}

Keywords: SM934; artemisinin analogue; ulcerative colitis; inflammatory bowel disease (IBD); neutrophils macrophage; NF-kB; RAW 264.7 cells; THP-1-derived macrophages

Acta Pharmacologica Sinica (2018) 39: 1633-1644; doi: 10.1038/aps.2017.185; published online 31 May 2018

\section{Introduction}

Ulcerative colitis (UC) is a chronic, nonspecific inflammatory bowel disease (IBD) characterized by complicated and relapsing inflammation in the gastrointestinal tract ${ }^{[1]}$. Multiple causes, including genetic, environmental, microbiological, and inflammatory factors, may contribute to the pathogenesis of UC, of which intestinal immune system dysfunction plays a direct role in the process of the disease ${ }^{[2]}$. A previous study showed that oral administration of DSS to mice could lead to clinical symptoms and histopathological features similar to

\footnotetext{
* To whom correspondence should be addressed.

E-mail jpzuo@simm.ac.cn (Jian-ping ZUO); tangwei@simm.ac.cn (Wei TANG)

Received 2017-11-19 Accepted 2017-12-21
}

those are observed in UC patients. Therefore, the DSS-induced mouse colitis model has been widely used to investigate the therapeutic effects of drug candidates for UC treatment ${ }^{[3]}$.

The innate immunity system acts as the first line of defense against intestinal lumenal pathogens. The intestinal lamina propria (LP) macrophage population, which is derived from circulating monocytes, increases in the active phase of $\operatorname{IBD}^{[4]}$. During the process of ulcerative colitis, activated macrophages produce excessive cytokines (IL-1, IL-6, TNF-a, etc) and reactive metabolites of oxygen and nitrogen. These accumulated pro-inflammatory factors not only trigger inflammatory responses by stimulating neutrophil migration and activating other lymphocytes ${ }^{[5]}$ but also promote intestinal epithelial tissue damage that enhances the dissemination of pro-inflammatory intestinal contents, including bacteria and 
their products ${ }^{[6]}$. Therefore, suppressing the population of LP macrophages or their functions may afford a new therapeutic strategy for UC.

NF-kB is a classical nuclear transcription factor frequently implicated in numerous diseases, including malignancies and inflammation $^{[7]}$. It has been shown that excessive activation of NF-kB plays a critical role at the onset and during the progression of experimental colitis, in which an abnormal level of intestinal inflammation is involved ${ }^{[8]}$. Neurath et al reported a striking expression of NF-kB family members in LP macrophages in IBD patients ${ }^{[9]}$. Additionally, clinical and histological signs of colitis in TNBS-induced colitic mice can be abrogated by local administration of antisense phosphorothioate oligonucleotides against the p65 subunit of NF-kB ${ }^{[10]}$. Thus, inhibition of NF-kB activation has been suggested as an antiinflammatory strategy against UC.

SM934, also known as $\beta$-aminoarteether maleate, which is a water-soluble artemisinin analogue, was identified as an immune modulator in our laboratory. Previously, we have demonstrated that SM934 exhibits strong immunosuppressive effects on autoimmune diseases, including systemic lupus erythematosus, experimental autoimmune encephalomyelitis, and rheumatoid arthritis, by regulating immune responses of $\mathrm{T}$ and $\mathrm{B}$ cells ${ }^{[11-15]}$. However, the protective effects of SM934 on UC remain unknown. In the present study, we sought to explore whether SM934 could act as a useful therapeutic agent against UC. Our findings showed that SM934 exhibited anti-inflammatory effects by suppressing macrophages and neutrophils and inhibiting the NF-kB signaling pathway, which offers new potential for the use of SM934 in the treatment of human UC.

\section{Materials and methods Reagents}

SM934 ( $\beta$-aminoarteether maleate) was synthesized from $\beta$-hydroxyarteether at Shanghai Institute of Materia Medica and dissolved in phosphate buffered saline (PBS) as a stock solution. Dextran sulfate sodium (DSS, molecular weight 36-50 kDa) was purchased from MP Biomedicals, Inc (Irvine, CA, USA). Cyclosporine (CsA) was purchased from the National Institutes for Food and Drug Control (Beijing, China). A fecal occult blood test kit was obtained from the Nanjing Jiancheng Bioengineering Institute (Nanjing, China). Phorbol 12-myristate 13-acetate (PMA) and lipopolysaccharide (LPS) were purchased from Sigma-Aldrich (St Louis, MO, USA). CCK-8 (Cell Counting Kit-8) was bought from Dojindo Molecular Technologies, Inc (Kumamoto, Japan). Proteinase and phosphatase inhibitors and the BCA assay kit were purchased from Thermo Scientific (Pittsburgh, PA, USA). Anti-phosphop65, anti-phospho-I-kB, anti-phospho-ERK1/2, and anti-iNOS (induced NO synthase) antibodies were bought from Cell Signaling Technology (Buckinghamshire, UK). Anti-mCD16/ CD32, FITC-anti-Gr-1, PE-anti-F4/80, and PercP-Cy5.5-antiCD11b antibodies and ELISA kits for mouse IL-1 $\beta$, IL-6, and TNF- $\alpha$ and human IL-1 $\beta$, IL-6, and TNF- $\alpha$ were purchased from eBioscience (San Diego, CA, USA).

\section{Cell culture}

RAW 264.7 (a murine macrophage cell line) and THP-1 (a human acute monocytic leukemia cell line) cells were purchased from the American Type Culture Collection (ATCC, Manassas, VA, USA). The cells were cultured in DMEM and RPMI-1640 medium (Gibco, Life), respectively, containing $10 \%$ fetal bovine serum (HyClone, Logan, UT, USA), 100 $\mathrm{U} / \mathrm{mL}$ penicillin and $100 \mathrm{\mu g} / \mathrm{mL}$ streptomycin. The cells were cultured in a humidified incubator with $5 \% \mathrm{CO}_{2}$ at $37{ }^{\circ} \mathrm{C}$. Differentiation of THP-1 cells was induced by 0.5 $\mu \mathrm{mol} / \mathrm{L}$ PMA for $3 \mathrm{~h}$ as described previously ${ }^{[16]}$. The cells were treated with $1 \mu \mathrm{g} / \mathrm{mL}$ LPS in the absence or presence of SM934.

\section{Mice}

Female BALB/c mice (6-8 weeks, 19-22 g) were obtained from Shanghai Lingchang Biotechnology Co, Ltd (Certificate № 2013-0018, Shanghai, China). All mice were housed under specific pathogen-free conditions, and all experiments were performed according to the guidelines of the Association for Assessment and Accreditation of Laboratory Animals Care International. All of the procedures were carried out strictly in accordance with the animal care and use protocol (2016-06ZJP-52) approved by the Institutional Animal Care and Use Committee (IACUC) at Shanghai Institute of Materia Medica.

\section{Induction of DSS colitis in mice and drug treatment}

Acute colitis was induced via administration of 5\% (w/v) DSS in drinking water. Mice received either regular drinking water (normal control) or DSS drinking water (model) for $7 \mathrm{~d}$ followed by regular drinking water for $3 \mathrm{~d}$ as described previously $^{[17]}$. Mice were randomly divided into 5 groups with 8 mice per group: untreated normal control, vehicle control, SM934 (3 or $10 \mathrm{mg} / \mathrm{kg}$ )-treated and CsA (20 mg/ kg, reference drug)-treated groups. SM934 and CsA were orally administered once daily for $10 \mathrm{~d}$ (Figure 1). Additionally, another five mice of each of the normal control, vehicle, CsA, and SM934 $(10 \mathrm{mg} / \mathrm{kg})$ groups were treated by the same methods but were sacrificed at $\mathrm{d} 7$ for isolating colonic LP lymphocytes.

\section{Disease activity index (DAI)}

The severity of colitis was evaluated by monitoring clinical manifestations daily, such as body weight, stool consistency and rectal bleeding ${ }^{[17]}$. The DAI was calculated based on the scoring system shown in Table 1 as previously described by Zhang et $a l^{[18]}$. Weight loss was defined as the difference between initial and testing weights, and diarrhea was defined as the absence of fecal pellet formation and the presence of continuous fluid fecal material in the colon. Occult blood was assessed using a fecal occult blood test kit. DAI values were calculated as the sum of the weight loss score, diarrhea score and rectal bleeding score. The DAI was determined by 3 investigators who were blinded to the experimental conditions. The clinical parameters used in the present study were chosen to represent the subjective clinical symptoms observed in human $\mathrm{UC}^{[19]}$. 


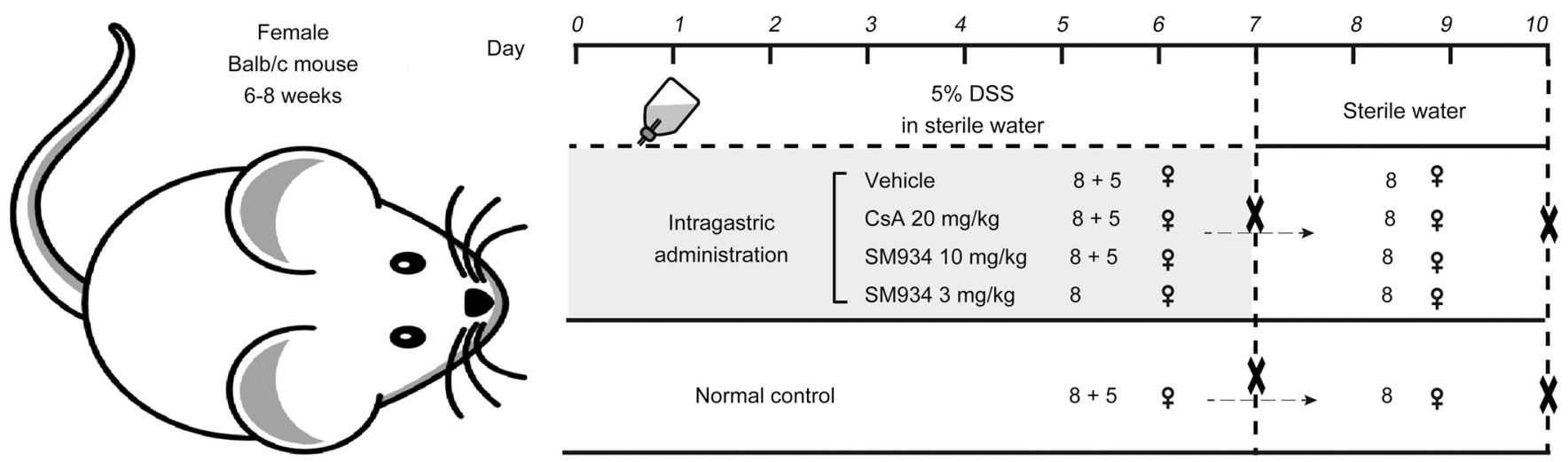

Figure 1. Experimental design of the induction of DSS colitis and drug treatment. Except normal control, acute colitis was induced by administration of $5 \%$ DSS dissolved in sterile drinking water for 7 days, after that the mice were administered with regular water for 3 days. Vehicle control (saline), SM934 (3 or $10 \mathrm{mg} / \mathrm{kg}$ ), and CsA (20 mg/kg) were given by intragastric administration from day 1 to 10 , respectively, five mice of each group were sacrificed at day 7 and the colons were isolated and subject to flow cytometry analysis.

Table 1. Criteria for disease activity index.

\begin{tabular}{llll}
\hline Weight loss (\%) & Stool consistency & Occult blood & Score \\
\hline$<0$ & Normal & Negative & 0 \\
$1-5$ & & + & 1 \\
$5-10$ & Loose & ++ & 2 \\
$10-20$ & & +++ & 3 \\
$>20$ & Diarrhea & Gross bleeding & 4 \\
\hline
\end{tabular}

Five grades of weight loss ( 0 , no loss or weight gain; $1,1 \%-5 \%$ loss; 2 , $5 \%-10 \%$ loss; $3,10 \%-20 \%$ loss; 4 , >20\% loss); three grades of stool consistency ( 0 , normal; 2 , loose; and 4 , diarrhea); five grades of occult blood (0, negative; $1,+; 2,++; 3,+++$; and 4 , gross bleeding).

\section{Histological processing and analysis}

Mice were sacrificed at the end of the experiment. The entire colon was dissected, flushed with ice-cold PBS and then stored at $-80^{\circ} \mathrm{C}$ for ex vivo analysis. Parts of the colons were fixed in $10 \%$ formalin and embedded in paraffin to provide sections for histological evaluation. The severity of colitis was evaluated in sections stained with hematoxylin and eosin (H\&E) by two independent observers blinded to the experimental conditions according to the criteria published by Santucci et $a l^{[20]}$. Histological evaluations of H\&E-stained colonic sections were graded as follows: 0 , no signs of inflammation; 1 , low leukocyte infiltration; 2 , moderate leukocyte infiltration; 3 , high leukocyte infiltration, moderate fibrosis, high vascular density, thickening of the colon wall, moderate goblet cell loss, and focal loss of crypts; and 4, transmural infiltrations, massive loss of goblet cells, extensive fibrosis, and diffuse loss of crypts.

Whole spleens from mice in each group were harvested, and the wet weight was measured. The spleen index was calculated as the wet weight of the spleen $(\mathrm{mg})$ divided by the body weight $(\mathrm{g})$. The MLNs were collected for flow cytometry analysis.

\section{Assessment of myeloperoxidase (MPO) activity}

Neutrophil infiltration into inflamed colonic mucosa was quantified by MPO activity assessment using the $o$-dianisidine method as previously described ${ }^{[21]}$. The results were shown as activity units per mg tissue.

\section{Single cell preparation and flow cytometry analysis}

To prepare single cell suspensions, spleens and MLNs from mice in each group were ground and filtered through a $40 \mu \mathrm{m}$ nylon mesh strainer. Colons isolated from mice induced by DSS for $7 \mathrm{~d}$ were cut into small pieces after fat was dissected away. Cleaned colon fragments were shaken in $\mathrm{Mg}^{2+}$ free Hanks' buffer saline with $5 \mathrm{mmol} / \mathrm{L}$ EDTA to dissociate epithelial cells and were then digested in RPMI-1640 medium with $5 \%$ BSA, $1 \mathrm{mg} / \mathrm{mL}$ collagenase, and $25 \mu \mathrm{g} / \mathrm{mL}$ DNase. The lamina propria lymphocytes were acquired by centrifugation in a Percoll gradient $(30 \%-70 \%)$ after filtering through a $67.5 \mu \mathrm{m}$ cell strainer ${ }^{[22]}$. The single-cell suspensions were blocked with anti-mCD16/CD32 (2.4G2) and then stained with FITC-anti-Gr-1, PE-anti-F4/80 and PercP-Cy5.5anti-CD11b antibodies. Flow cytometric analysis was performed on the BD LSRFortessa, and data were analyzed using FlowJo 7.6 software (Treestar, Ashland, OR, USA).

\section{Immunofluorescence analysis}

Colonic tissues were embedded in OCT compound and sectioned on a cryostat ( $6 \mu \mathrm{m}$ thick). After fixation in paraformaldehyde (PFA), sections were blocked with 5\% BSA for 60 min and then incubated with FITC-anti-CD11b (1:100, R\&D systems, Minneapolis, MN, USA) or FITC-anti-F4/80 (1:50, Santa Cruz, CA, USA) at $4{ }^{\circ} \mathrm{C}$ overnight. The sections were counterstained with 4', 6-diamidino-2-phenylindole (DAPI). Fluorescent cells were visualized and digital images were captured using a Leica TCS SP8 STED confocal microscope.

Quantitative real-time polymerase chain reaction (qRT-PCR) analysis Total RNA was isolated from colon tissues, and real-time 
PCR was performed as described in our previous study ${ }^{[23]}$. Mouse rpl13a was used as a housekeeping gene. The primer sequences used were as follows: mouse rpl13a, forward, $5^{\prime}$-GAG GTC GGG TGG AAG TAC CA- ${ }^{\prime}$, and reverse, $5^{\prime}$-TGC ATC TTG GCC TTT TCC TT- $3^{\prime}$; mouse $I L-1 \beta$, forward, $5^{\prime}$-GAA ATG CCA CCT TTT GAC AGT G-3' , and reverse, $5^{\prime}$-TGG ATG CTC TCA TCA GGA CAG-3'; mouse IL-6, forward, $5^{\prime}$-CTG CAA GAG ACT TCC ATC CAG- $3^{\prime}$, and reverse, $5^{\prime}$-AGT GGT ATA GAC AGG TCT GTT GG-3'; mouse TNF- $a$, forward, $5^{\prime}$-CAG GCG GTG CCT ATG TCT C-3', and reverse, 5'-CGA TCA CCC CGA AGT TCA GTA G-3'; mouse iNOS, forward, 5'-CAA CAT CAG GTC GGC CAT CAC T-3', and reverse, $5^{\prime}$-ACC AGA GGC AGC ACA TCA AAG C-3'; and mouse MIP-1a, forward, 5'-GCC ATA TGG AGC TGA CAC-3', and reverse, 5'-TGC CTC CAA GAC TCT CAG-3'.

\section{Cytokine analysis by ELISA}

Colons from mice in each group were homogenized with lysis buffer to extract total protein as described by Janice J KIM et $a l^{[21]}$. The concentration of total protein was determined by the BCA protein assay kit. The levels of IL-1 $\beta$, IL- 6 , and TNF- $\alpha$ in colon homogenates and cell culture supernatants were quantified by an ELISA kit according to the manufacturer's protocol.

\section{Cytotoxicity assessment}

RAW 264.7 cells and THP-1-derived macrophages were seeded at a concentration of $5 \times 10^{4}$ cells/well in 96-well culture plates overnight and were then supplemented with different concentrations of SM934. After incubation for $24 \mathrm{~h}$, cell viability was measured by CCK-8 assay according to the manufacturer's instructions.

\section{NO production and quantification}

The NO production of RAW 264.7 cells was detected by the Griess assay as previously described ${ }^{[24]}$.

\section{Immunofluorescence cytochemistry}

RAW 264.7 and THP-1-derived macrophages on coverslips were fixed in $4 \%$ PFA for $30 \mathrm{~min}$ and were permeabilized with $1 \%$ Triton X-100 for 10 min. After blocking with 3\% BSA for $1 \mathrm{~h}$, cells were incubated with rabbit anti-iNOS or antiphosphorylated p65 $(1: 100)$ at $37^{\circ} \mathrm{C}$ for $2 \mathrm{~h}$. After washing with 1\% PBS-Tween, Alexa Fluor 647-conjugated anti-rabbit secondary antibodies were added. Negative control reactions were included in each experiment and carried out by replacing primary antibodies with PBS. The cells were counterstained with DAPI. All images were captured using a Leica confocal microscope.

\section{Western blot analysis}

Colon tissues were homogenized in sodium dodecyl sulfate sample buffer containing proteinase and phosphatase inhibitor. THP-1-derived macrophages were lysed with RIPA lysis buffer (Beyotime, Shanghai, China). Supernatants were collected, and protein concentrations were then measured using the BCA assay kit. The total protein samples were separated by sodium dodecyl sulfate-polyacrylamide gel electrophoresis and transferred to nitrocellulose membranes (Amersham Pharmacia Biotech, Buckinghamshire, UK). After blocking, the membranes were incubated with anti-phosphoNF-KB, anti-phospho-I-KB, or anti-phospho-ERK1/2. After washing with TBS with Tween-20, the secondary antibodies (1:2000, Bio-Rad, Richmond, CA, USA) were added, and HRP-conjugated monoclonal mouse anti-GAPDH (1:10000, Kangcheng, Shanghai, China) was used as a control for normalization. Signals were detected with an ECL system (Amersham Bioscience, Buckinghamshire, UK) and exposed to classic autoradiography film.

\section{Statistical analysis}

Data were presented as the mean \pm SEM and statistically evaluated by one-way ANOVA followed by Dunnett's test between the vehicle control group and multiple dose group. Statistical analyses were conducted using GraphPad Prism 5.0 software.

\section{Results}

\section{SM934 attenuated colitis in DSS-treated mice}

Sustained body weight loss, diarrhea and rectal bleeding are the typical features in the DSS-induced mouse model of ulcerative colitis ${ }^{[25]}$. As shown in Figure 2A, mice in the vehicle control group exhibited dramatic body weight loss, but SM934 and CsA significantly attenuated the loss of body weight. SM934 also dose dependently reduced the DSS-mediated increase in DAI scores during the disease progression (Figure 2B). Compared with vehicle controls, colon shortening was restored in CsA- and SM934-treated groups $(P<0.05$, Figure 2C and 2E). In addition, DSS caused an increase in spleen weight that was generally correlated with the extent of inflammation and anemia. Both SM934 and CsA significantly reversed the DSS-mediated increase in the spleen index $(P<0.05$, Figure 2D and $2 \mathrm{~F}$ ).

SM934 alleviated colonic epithelial injury and reduced the percentage of macrophages and neutrophils in spleens and MLNs from DSS-treated mice

DSS caused epithelial injury, including diffuse damage of crypt structures, loss of goblet cells, and substantial neutrophil infiltration into the $\mathrm{LP}^{[17]}$. The severity of colonic ulceration and inflammation was further examined by histopathological analysis using H\&E staining and MPO activity measurement. The results showed that SM943-treated mice exhibited relative intact colonic architecture with no apparent ulceration and less inflammatory cell infiltration (Figure 3A and 3B). MPO is released from the cytoplasmic granules of activated phagocytes, and neutrophil infiltration was further measured by MPO activity in colon tissues. As shown in Figure 3C, SM934 at 3 and $10 \mathrm{mg} / \mathrm{kg}$ significantly attenuated DSS-induced hyperactivated MPO activity $(P<0.05)$. Additionally, flow cytometry analysis demonstrated that the percentages of macrophages $\left(\mathrm{CD} 11 \mathrm{~b}^{+} \mathrm{F} 4 / 80^{+}\right)$and neutrophils $\left(\mathrm{CD} 11 \mathrm{~b}^{+} \mathrm{Gr}-\mathrm{1}^{+}\right)$in spleens and MLNs were reduced after SM934 treatment compared with the vehicle control (Figure 3D-E). 

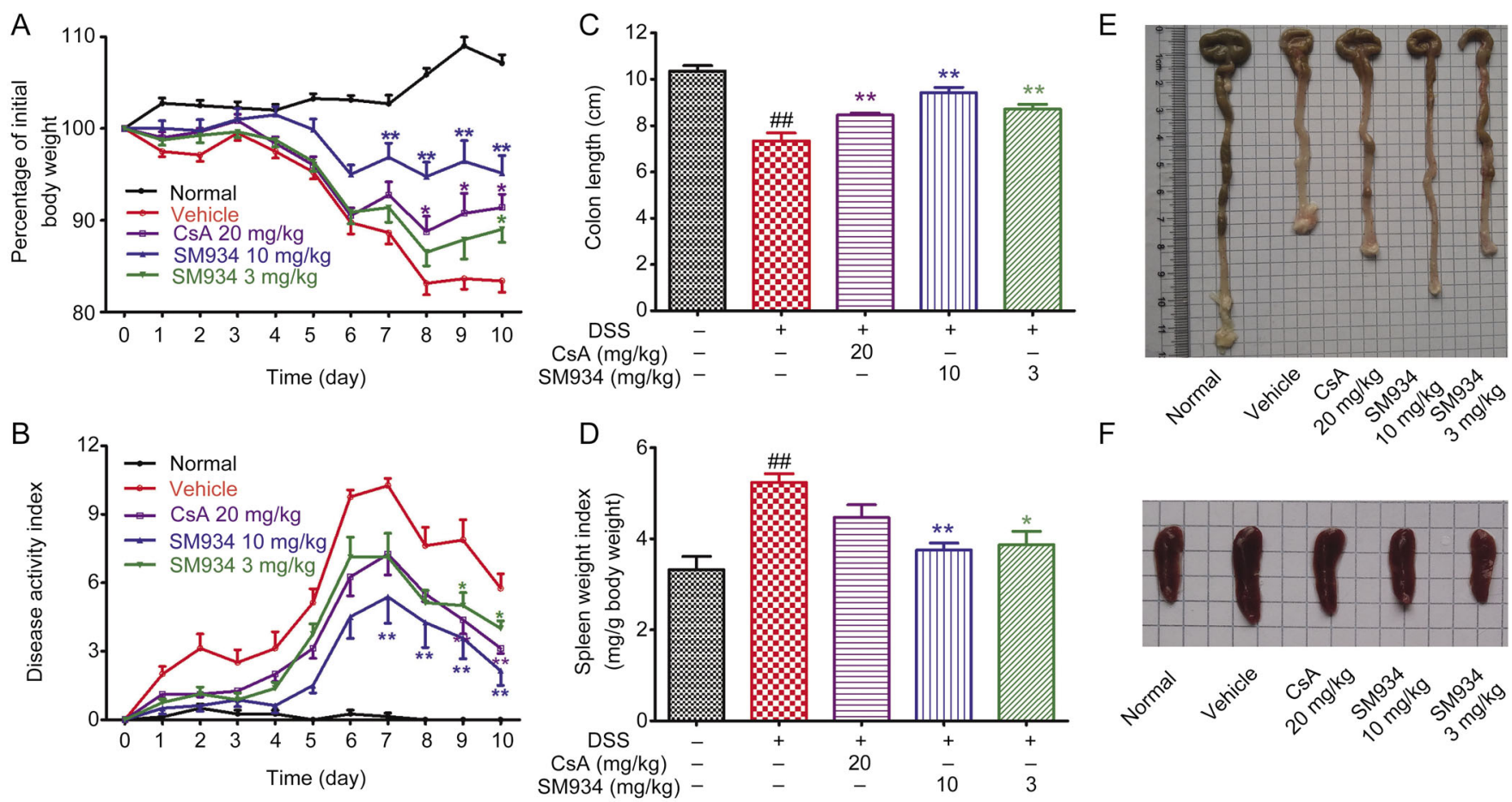

Figure 2. SM934 treatment ameliorated the symptoms of DSS-induced experimental colitis in mice. (A) Loss of basal body weight of each group mice after DSS induction. (B) DAl evaluations of each group mice. (C) Colon length of each mouse. (D) Spleen weight index of each group mice. Macroscopic appearances of colons $(\mathrm{E})$ and spleens $(\mathrm{F})$. Data are presented as means $\pm \mathrm{SEM}(n=8)$. In (A, B) ${ }^{*} P<0.05,{ }^{* *} P<0.01$ vs vehicle control group at the same day. In (D, F) ${ }^{\# \#} P<0.01$ vs normal control group; ${ }^{*} P<0.05$, ${ }^{* *} P<0.01$ vs vehicle control group. Results are from 1 of 3 independent experiments with similar results.

\section{SM934 reduced production of pro-inflammatory mediators in colon tissues of DSS-treated mice}

Increased production of pro-inflammatory mediators, such as IL-1 $\beta$, IL-6, TNF- $\alpha$, iNOS and macrophage inflammation protein-1a (MIP-1a), plays a critical role in DSS-induced ulcerative colitis ${ }^{[25]}$. To investigate the influence of SM934 on the gene expression of inflammation-associated molecules, qRTPCR analysis was performed. Figure $4 \mathrm{~A}$ and $4 \mathrm{~B}$ shows that SM934 significantly inhibited the gene expression of these cytokines and chemokines in the colon tissues. Furthermore, an ELISA assay was also performed to confirm the effects of SM934 on the protein expression of these cytokines. As shown in Figure $4 C$, similar to the results obtained at the transcription level, a notable increase in IL- $1 \beta$ levels in the colon tissues of the DSS treatment group $(70.54 \pm 2.31 \mathrm{pg} / \mathrm{mg})$ was also observed compared to the levels of the control group (10.91 \pm $0.85 \mathrm{pg} / \mathrm{mg}$ ). IL-1 $\beta$ levels were significantly lower in the CsAtreated group $(40.61 \pm 3.73 \mathrm{pg} / \mathrm{mg})$ and SM934-treated group $(10 \mathrm{mg} / \mathrm{kg}, 27.47 \pm 2.13 \mathrm{pg} / \mathrm{mg})(P<0.05)$. The increased IL-6 level in the DSS treatment group $(86.04 \pm 5.08 \mathrm{pg} / \mathrm{mg})$ compared to the control group $(36.95 \pm 1.03 \mathrm{pg} / \mathrm{mg})$ was also downregulated in the SM934 group (10 mg/ $\mathrm{kg}, 51.38 \pm 3.35 \mathrm{pg} / \mathrm{mg})$. In addition, the tissue TNF- $\alpha$ levels were significantly decreased by SM934 treatment $(10 \mathrm{mg} / \mathrm{kg}, 65.08 \pm 3.94 \mathrm{pg} / \mathrm{mg})$ compared to the vehicle-treated group $(96.32 \pm 1.34 \mathrm{pg} / \mathrm{mg})(P<0.05)$.
SM934 inhibited macrophage and neutrophil infiltration in colons in DSS-induced colitis mice

It has been reported that increased expression of CD11b, which is the surface marker of many leukocytes, including monocytes, neutrophils, granulocytes, macrophages, and natural killer cells, can be used to monitor inflammation ${ }^{[26]}$. To further explore the possible protective mechanism of SM934 on DSSinduced acute colitis, we examined CD11b and F4/80 (macrophage surface marker) expression in colon tissues. As shown in Figure $5 \mathrm{~A}$ and $5 \mathrm{~B}$, a large number of $\mathrm{CD} 11 \mathrm{~b}^{+}$or $\mathrm{F} 4 / 80^{+}$ inflammatory cells that accumulated at the mucosa of the lesion site were detected in colonic tissues from DSS-treated mice, while a dramatic reduction of these cells was observed in SM934-treated colonic tissues. In addition, the accumulation of macrophages and neutrophils in colonic LP were exam-

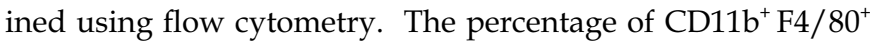

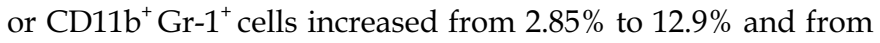
$3.73 \%$ to $16.7 \%$, respectively, upon DSS treatment and was then reduced to $5.01 \%$ and $6.0 \%$, respectively, after SM934 treatment (Figure 5C-F, $P<0.05$ ).

\section{SM934 suppressed activation of the NF-KB pathway in DSS-treated mice}

It has been reported that the NF-kB and mitogen-activated protein kinase (MAPK) pathways may play crucial roles in DSS-induced colonic inflammation ${ }^{[27,28]}$. Therefore, we exam- 
A
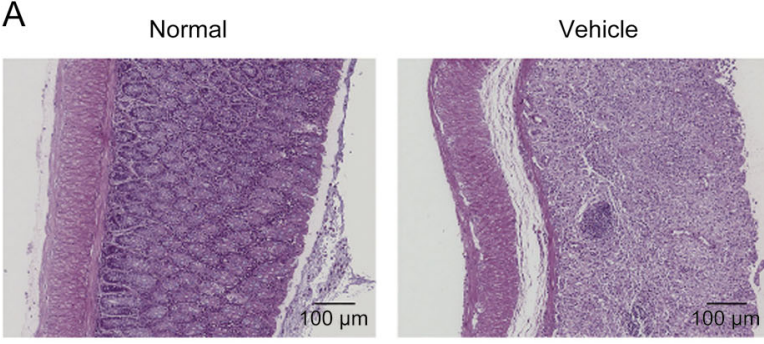

SM934 $10 \mathrm{mg} / \mathrm{kg}$

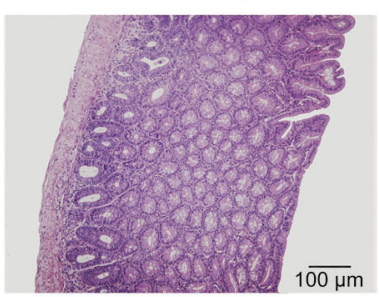

SM934 3 mg/kg

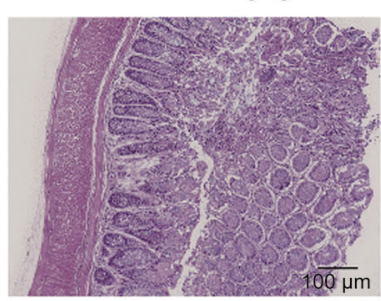

$\mathrm{D}$

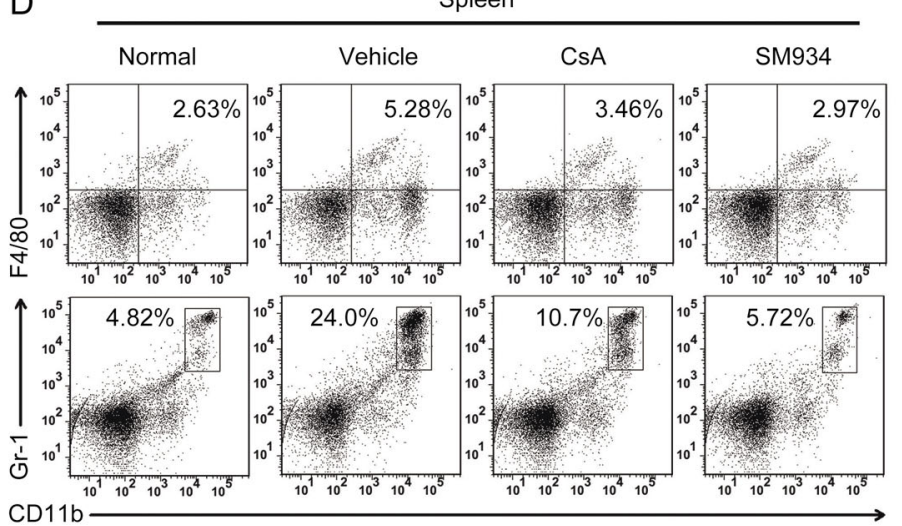

CsA $20 \mathrm{mg} / \mathrm{kg}$

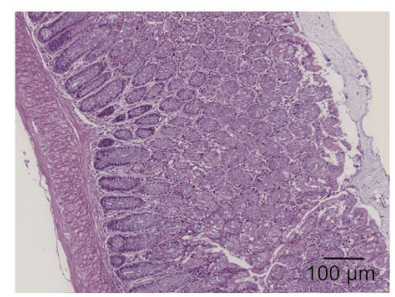

DSS
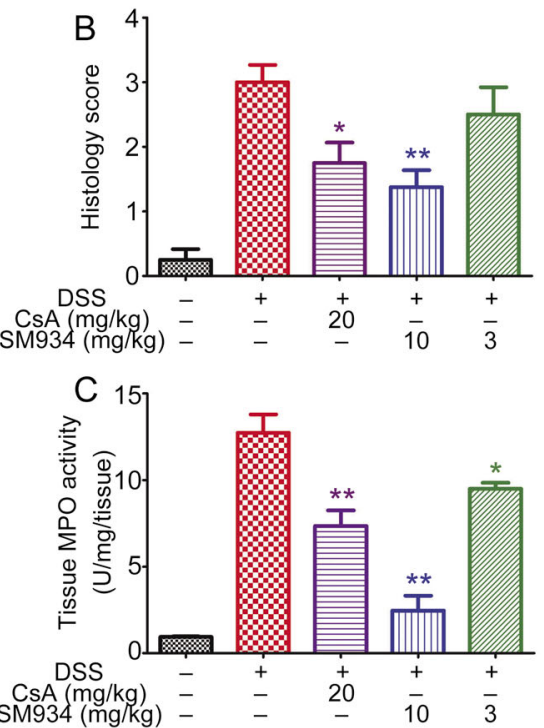

E
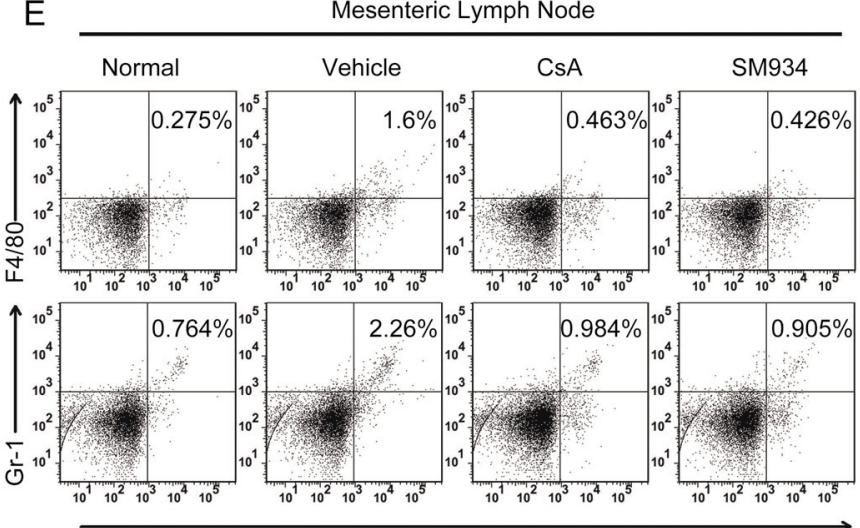

Figure 3. SM934 alleviated the epithelial injury and neutrophil infiltration in DSS-induced colitic mice. (A) H\&E stained colonic sections. (B) Histopathological scores of colonic section of each group mice. (C) MPO activity in the colonic homogenates. Representative FACS blots of CD11 $\mathrm{b}^{+}$Gr- $1^{+}$ and $\mathrm{CD} 11 \mathrm{~b}^{+} \mathrm{F} 4 / 80^{+}$cells in spleens (D) and MLNs (E). Data are presented as mean $\pm \mathrm{SEM}(n=8) .{ }^{*} P<0.05,{ }^{* *} P<0.01$ vs vehicle control group.

A

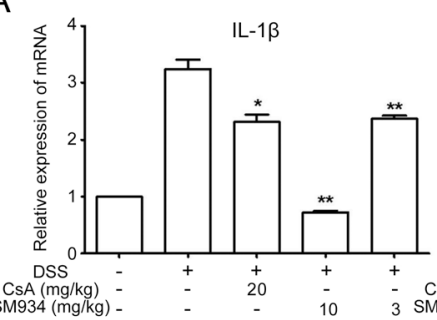

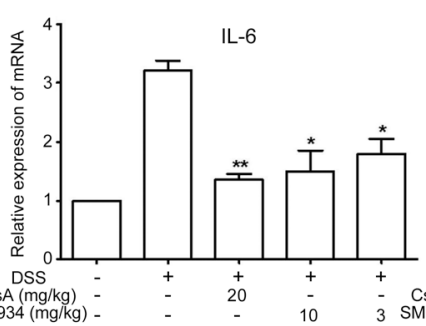

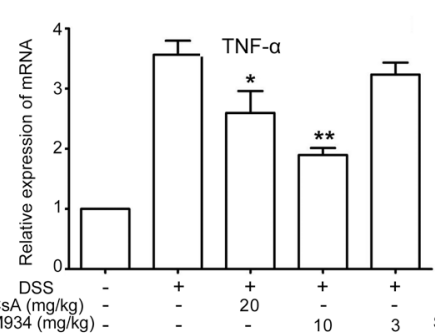

B

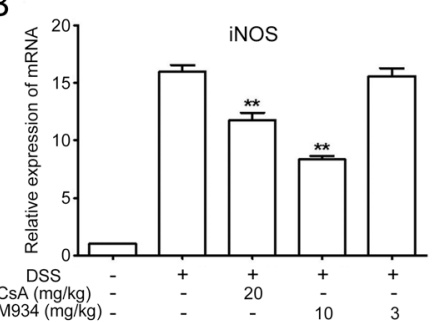

C

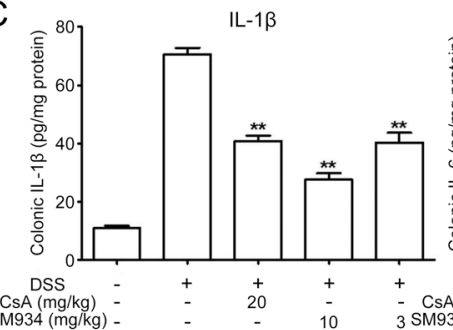

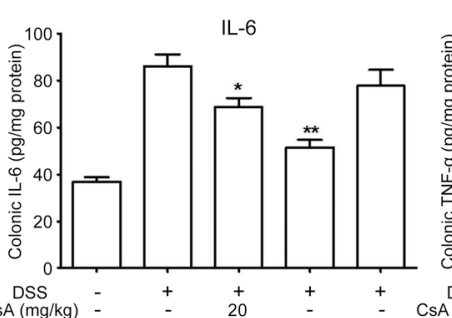

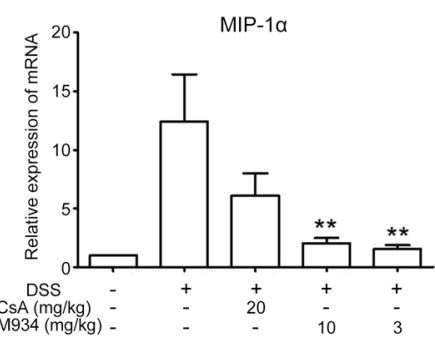

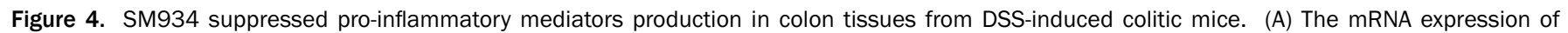
cytokines IL-1 $\beta$, IL-6 and TNF- $\alpha$ and (B) iNOS and chemokines MIP-1 $\alpha$ in colonic tissues. (C) Protein levels of cytokines including IL-1 $\beta$, IL- 6 and TNF- $\alpha$ in colonic homogenates. Data are presented as mean \pm SEM $(n=8) .{ }^{*} P<0.05,{ }^{* *} P<0.01$ vs vehicle control group. 
A DAPI
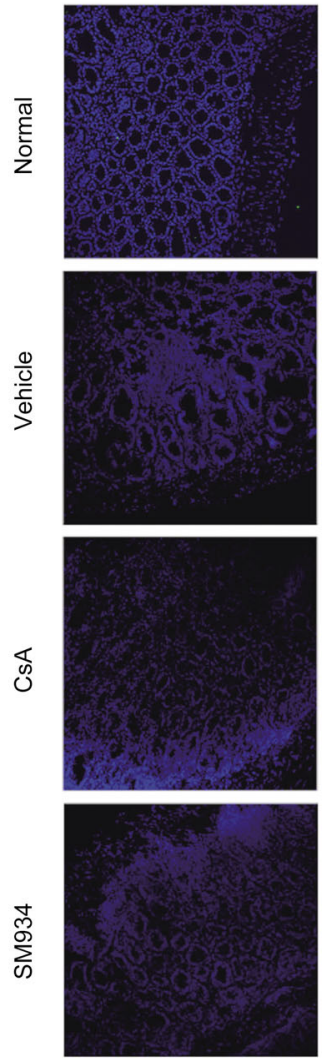

C
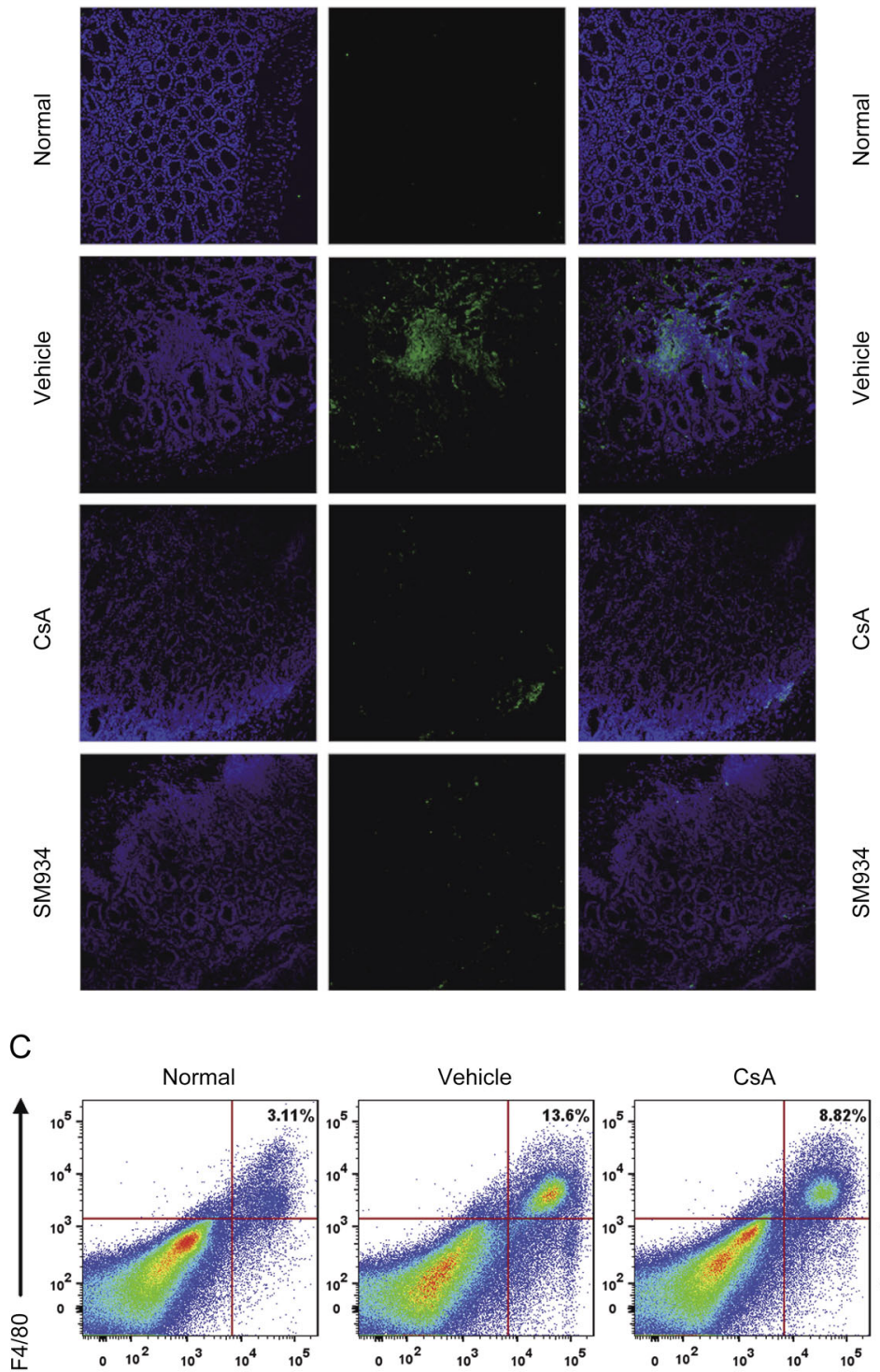

\section{৫্র}
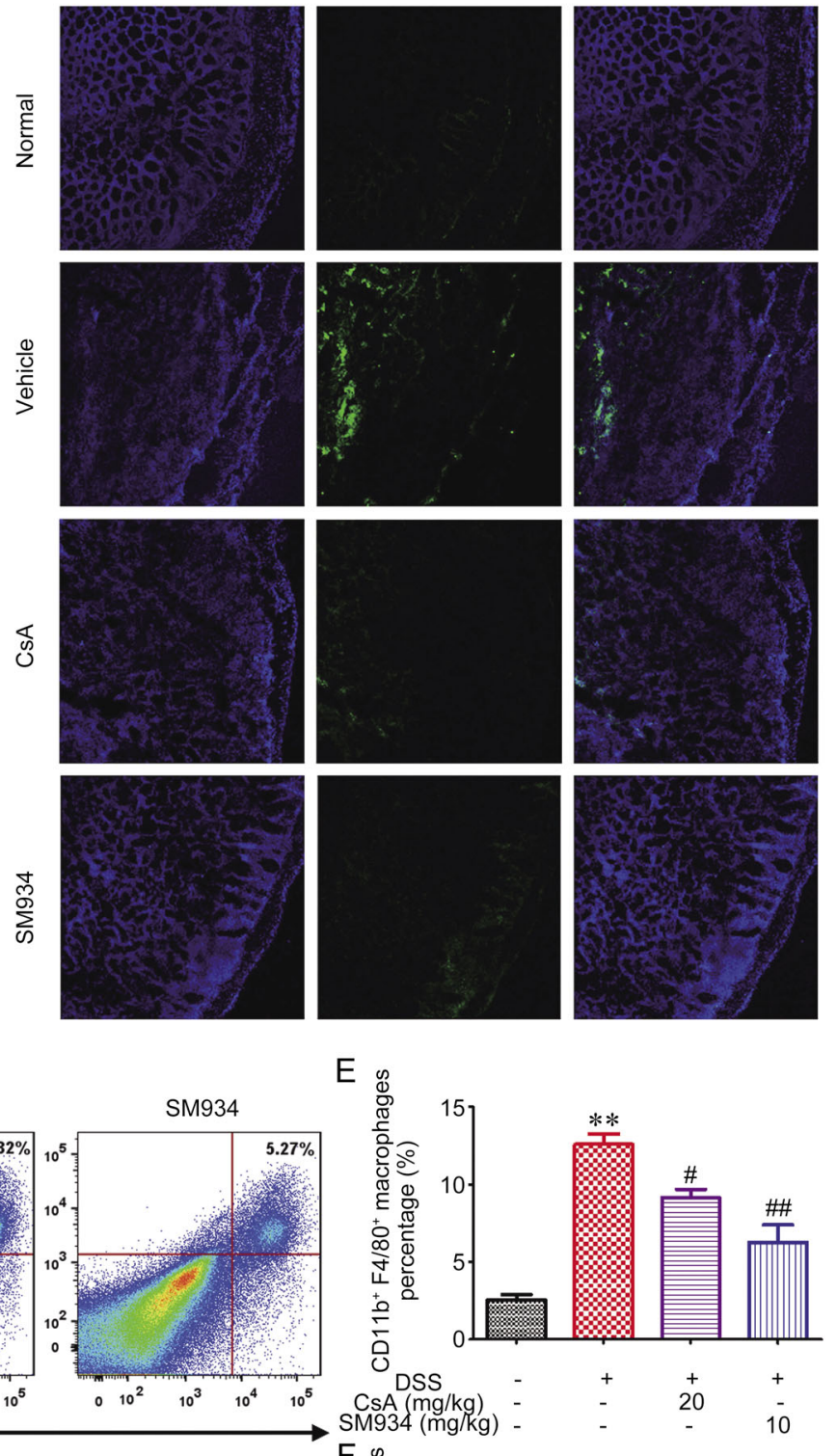

D
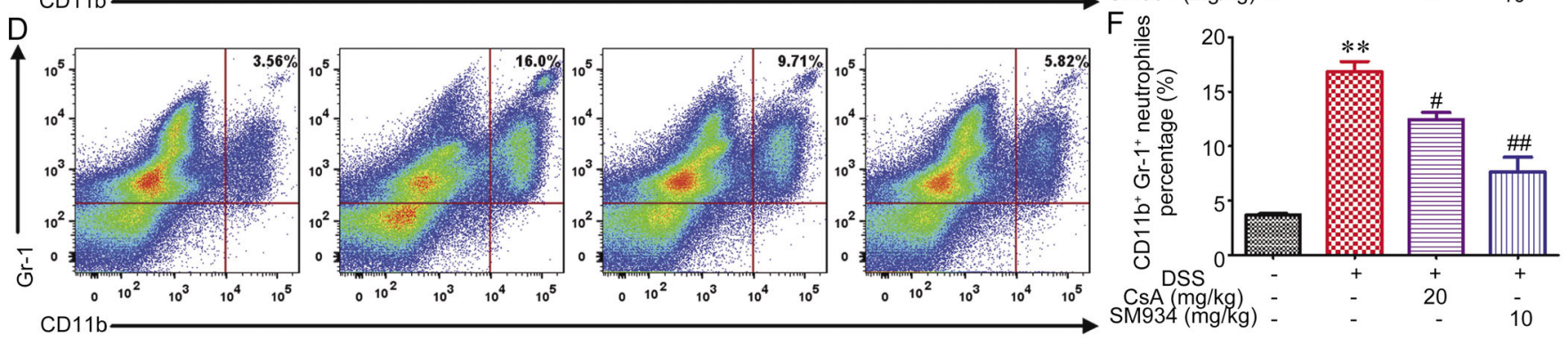

Figure 5. SM934 inhibited macrophages and neutrophils infiltration in colons from DSS-induced colitis mice. Sections of colonic tissues were immunostained with DAPI (blue) and FITC-anti-CD11b (green) (A) or FITC-anti-F4/80 (B) and observed by confocal laser-scanning microscope. The percentage of macrophages (CD11 $\mathrm{b}^{+} \mathrm{F} 4 / 80^{+}$cells) $(\mathrm{C})$ and neutrophils (CD11 $\mathrm{b}^{+} \mathrm{Gr}-1^{+}$cells) (D) in intestinal LP lymphocytes of DSS induced mice was measured by FACS analysis. Data shown are the mean \pm SEM of the mean five mice per group. ${ }^{*} P<0.05$, ${ }^{* *} P<0.01$ vs vehicle control group.

ined whether SM934 could affect NF-kB and/or MAPK signaling. NF-KB localization in the colon is illustrated in Figure 6A. SM934 and CsA markedly inhibited NF-KB activity, as indicated by the decreased phosphorylation of NF-кB and ІкB (Figure 6B and 6C) $(P<0.05)$. The increased phosphorylation of ERK1/2 induced by DSS was also abrogated by SM934 or 
CsA treatment (Figure 6B and 6D) $(P<0.05)$.

SM934 inhibited the secretion of pro-inflammatory mediators in LPS-stimulated RAW 264.7 cells

To evaluate the anti-inflammatory effects of SM934 in vitro, RAW 264.7 cells were stimulated by LPS to mimic M1-like macrophages. A cytotoxicity test indicated that the concentrations of SM934 applied in the subsequent experiments exhibited no obvious influence on cell viability (Figure 7A). Figure 7B-C shows that SM934 inhibited the secretion of IL-6 and TNF- $\alpha$ in a dose- dependent manner. The phosphorylation of p65 and ERK1/2 induced by LPS was also reduced by SM934 treatment (Figure 7D). Further, the secretion of NO was also suppressed by SM934 treatment (Figure 7E), and immunocytochemistry data demonstrated that SM934 inhibited the expression of iNOS (Figure 7F).

SM934 suppressed the secretion of pro-inflammatory cytokines through inhibition of the NF-kB signaling pathway in THP-1 derived macrophages

To extend our observations, the effects of SM934 on cytokine
A

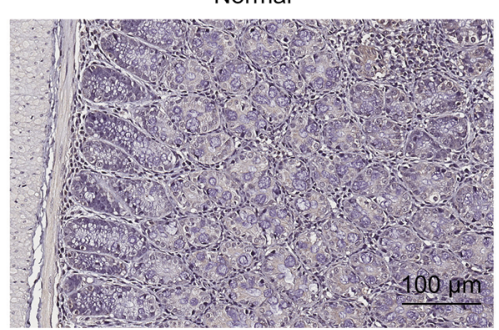

SM934 $10 \mathrm{mg} / \mathrm{kg}$

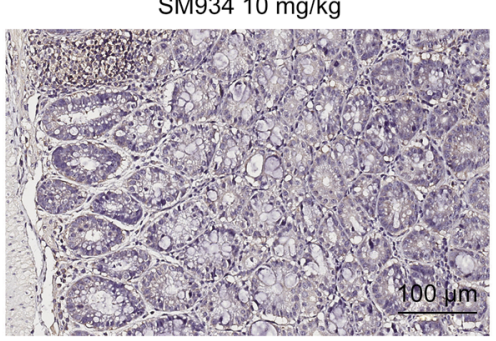

Vehicle

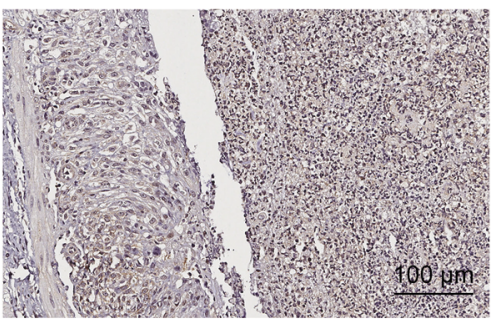

SM934 $3 \mathrm{mg} / \mathrm{kg}$

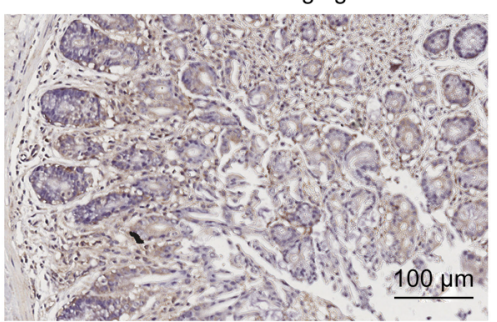

CsA $20 \mathrm{mg} / \mathrm{kg}$
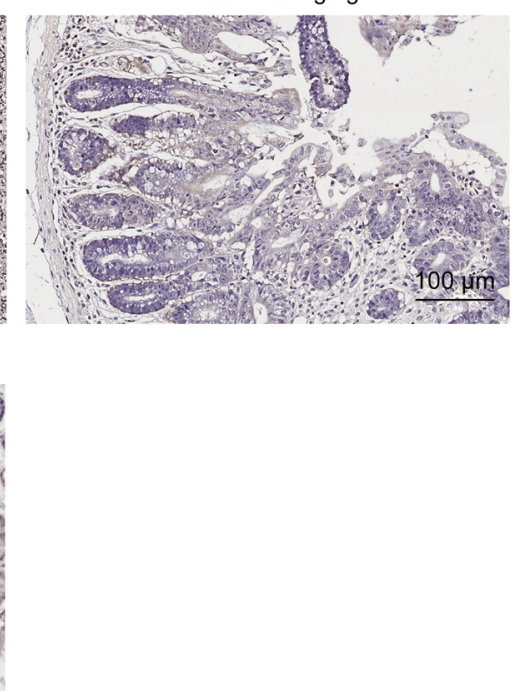

B

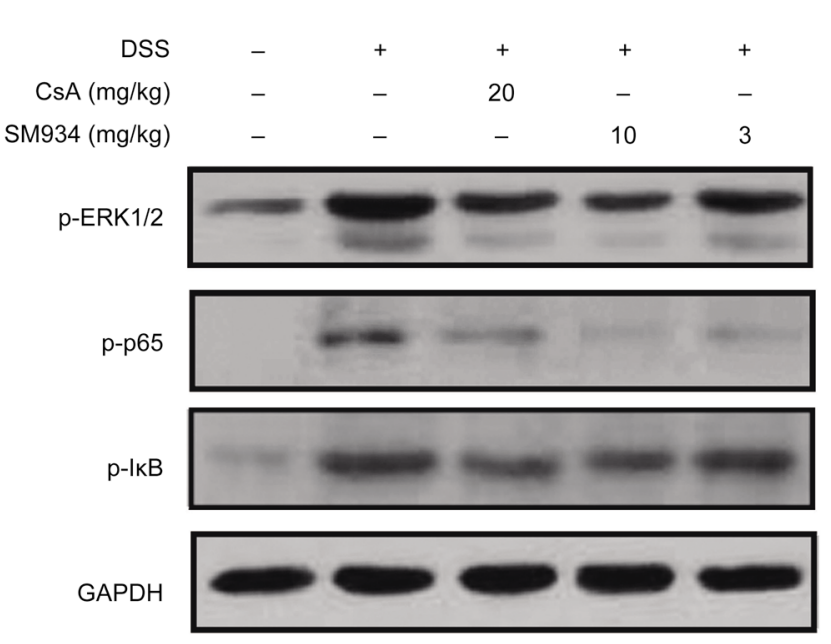

C

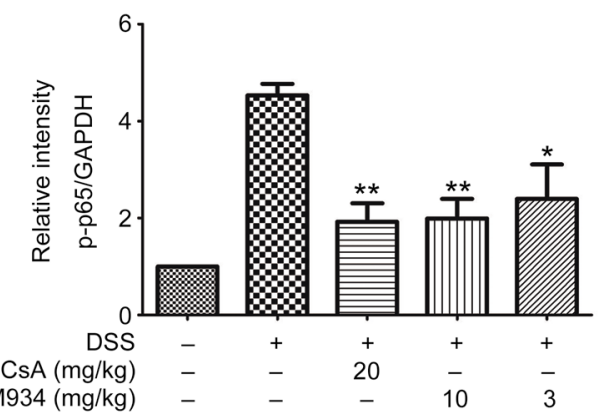

D

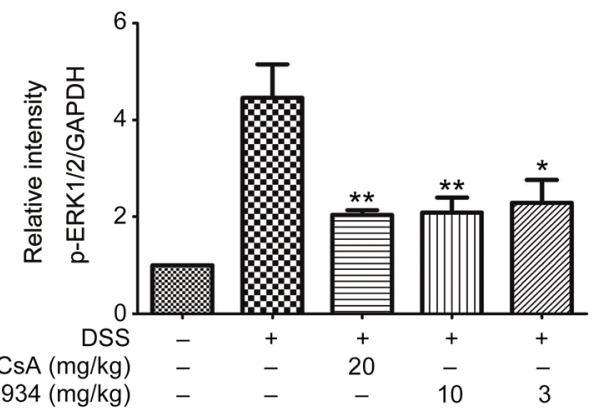

Figure 6. SM934 regulated NF-KB signaling pathway in colon tissue of DSS-induced colitis mice. (A) Immunohistochemical staining of NF-kB in colonic tissues. (B) Immunoblot analysis of the level of p-p65, p-IkB, p-ERK1/2 in the colonic homogenates from each group. Phosphorylations of p65 (C) and ERK1/2 (D) were normalized to GAPDH, data are presented as mean \pm SEM of three independent experiments. ${ }^{*} P<0.05$, ${ }^{* *} P<0.01$ vs vehicle control group. 


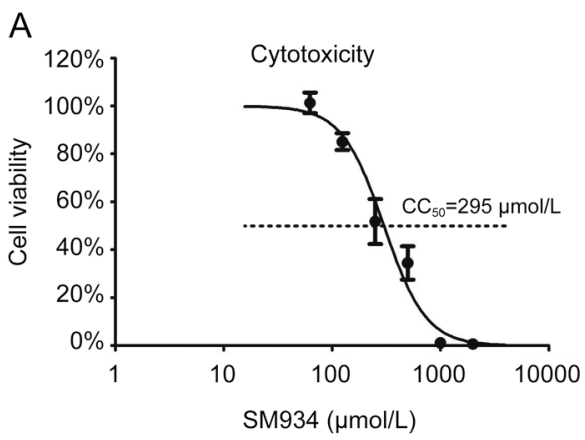

D

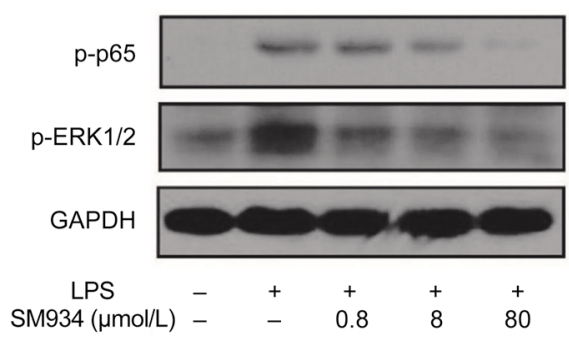

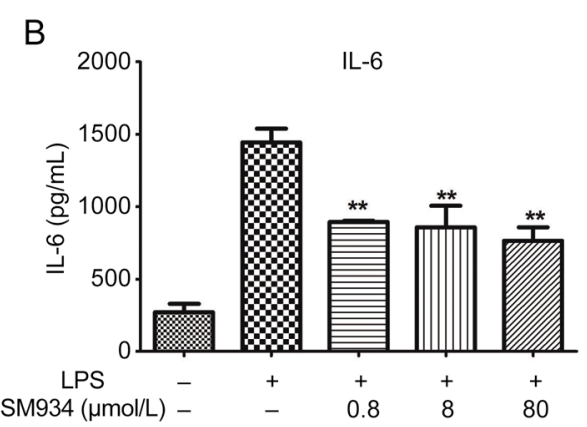

E

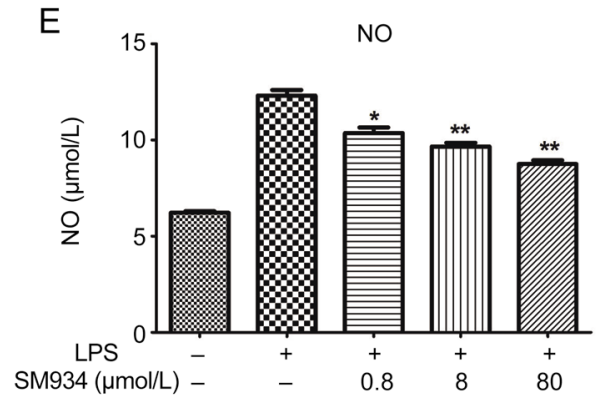

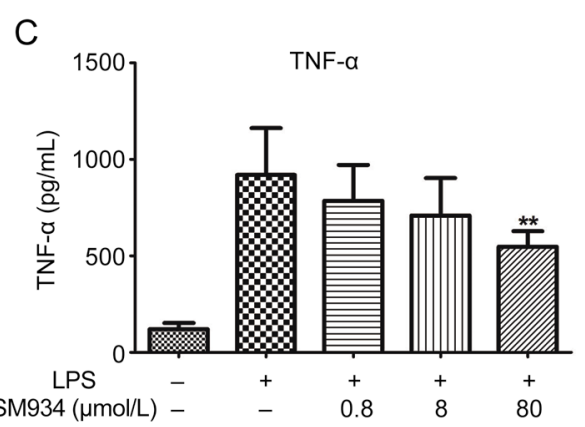

F
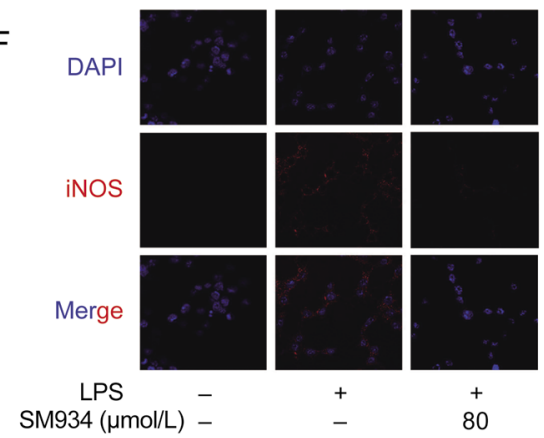

Figure 7. SM934 inhibited the secretion of pro-inflammatory mediators, activation of NF-KB, MAPK cell signaling and activation of iNOS in LPS stimulated RAW 264.7 cells. RAW 264.7 cells were stimulated with LPS $(1 \mu \mathrm{g} / \mathrm{mL})$ and treated with the indicated concentration of SM934 for $24 \mathrm{~h}$ (A$\mathrm{C}$ and $\mathrm{E})$. (A) The effect of SM934 on viability of RAW 264.7 cells were examined by CCK 8 assays. The secretion of IL- 6 (B) and TNF- $\alpha$ (C) were detected by ELISA in the supernatant of cell culture. Phosphorylation of p65 and ERK1/2 were detected by Western blot (D). The secretion of NO was measured by Griess reaction and expression of iNOS was detected by immunofluorescence ( $E$ and $F$ ). Data are presented as mean \pm SEM of three independent experiments. " $P<0.05,{ }^{* *} P<0.01$ vs LPS group.

secretion and activation of NF- $\mathrm{KB}$ in PMA-differentiated THP-1 cells were further investigated. Cytotoxicity analyses indicated that the concentrations of SM934 applied in the subsequent experiments exhibited no obvious influence on cell viability (Figure 8A). Figure 8B-D shows that SM934 inhibited IL-1 $\beta$, IL-6 and TNF- $\alpha$ secretion in a dose-dependent manner. Western blot analysis confirmed that SM934 significantly suppressed LPS-induced NF-KB phosphorylation of p65 in THP-1 derived macrophages (Figure $8 \mathrm{E}$ ). Immunofluorescence staining showed that THP-1 cells stimulated with LPS exhibit a dramatic increase in the translocation of NF-KB into the nucleus, whereas the LPS-induced NF-KB nuclear translocation was markedly inhibited by SM934 treatment (Figure 8F).

\section{Discussion}

Ulcerative colitis (UC) is one of the two major forms of inflammatory bowel disease (IBD) in humans and has become a heavy societal burden due to its increasing prevalence and incidence ${ }^{[29]}$. Due to many undesirable side effects of the current existing therapies, more efficient therapeutic agents with no or few side effects are urgently needed. The present study aimed to investigate the efficacy and underlying mechanisms of a water-soluble artemisinin analogue, SM934, in alleviating DSS-induced colitis in mice. We found that SM934 significantly attenuated DSS-induced colonic inflammatory responses by suppressing macrophages and neutrophils and inhibiting the NF-KB signaling pathway in vivo. Moreover,
SM934 was shown to suppress the secretion of pro-inflammatory cytokines through inhibition of the NF- $\mathrm{kB}$ signaling pathway in vitro. These results suggest that SM934 might be a new useful therapeutic agent for treating UC.

DSS-induced colitis is a well-characterized experimental colitis model for investigating the contribution of innate immune mechanisms in intestinal inflammation, as the acute inflammatory response is independent of $\mathrm{T}$ and $\mathrm{B}$ cells ${ }^{[30]}$. In this acute colitis model, the recruitment and infiltration of innate immune system cells, especially neutrophils and macrophages, are critical to the onset of an intestinal inflammatory reaction. After activation, infiltration leucocytes release reactive oxygen species and other pro-inflammatory mediators, and then, the integrity of the intestinal epithelial barrier is broken, which accelerates disease processes. Thus, the innate immune system plays a critical role in the pathogenesis of acute ulcerative colitis by initiating a rapid and effective inflammatory response against the invasion of luminal antigens ${ }^{[2,31]}$.

SM934, among synthetized artemisinin derivatives, is a novel water soluble artemisinin analogue and was recently approved by the China Food and Drug Administration for clinical trials as a new therapeutic agent ${ }^{[32]}$. It has been reported that SM934 treatment exhibits promising therapeutic effects on multiple autoimmune diseases, including rheumatoid arthritis ${ }^{[13]}$, systemic lupus erythematosus ${ }^{[33]}$ and multiple sclerosis ${ }^{[12]}$, primarily through inhibiting the adaptive 

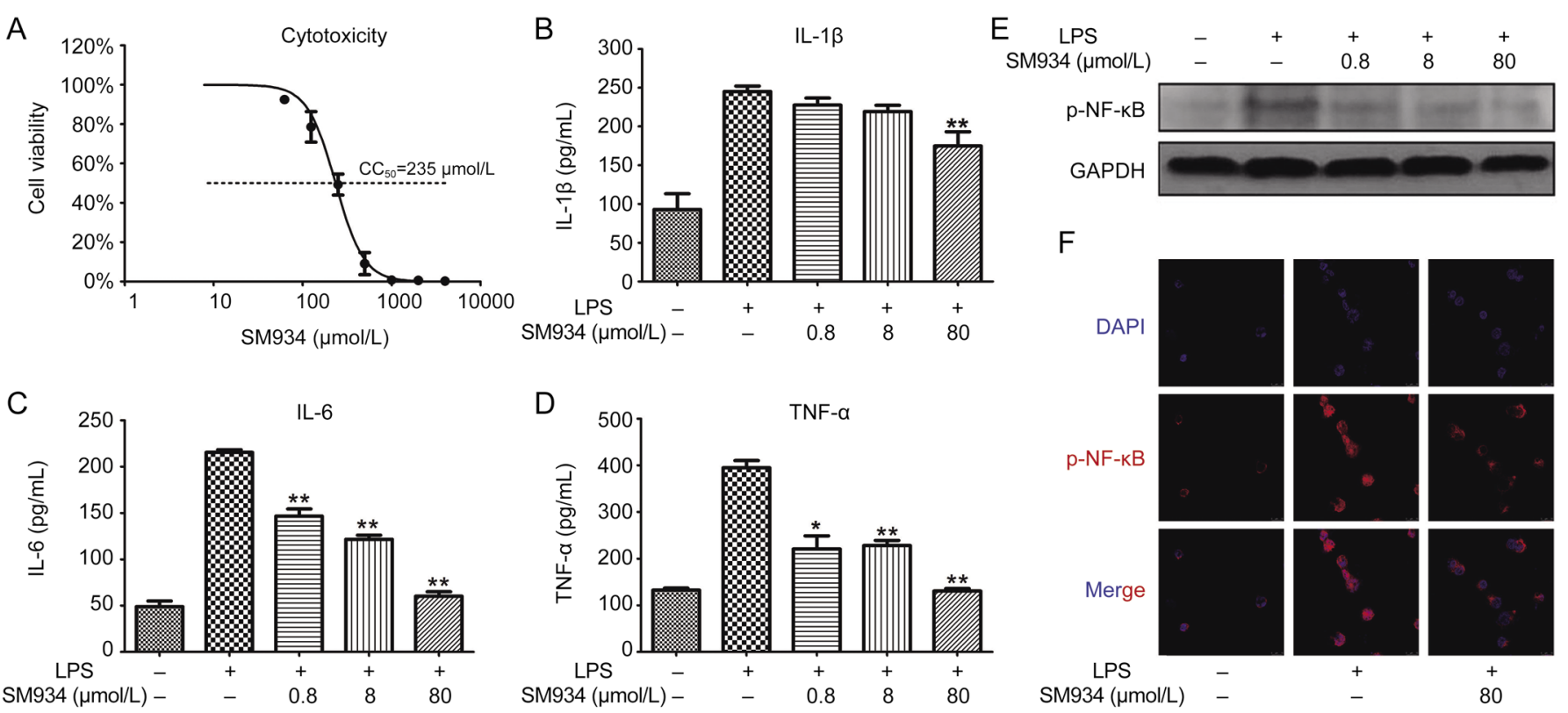

Figure 8. SM934 suppressed the secretion of pro-inflammation cytokines and inhibited the phosphorylation and translocation of NF-kB in THP-1derived macrophages. PMA differentiated THP-1 cells were stimulated with LPS (1 $\mathrm{\mu g} / \mathrm{mL})$ and treated with the indicated concentration of SM934 for $24 \mathrm{~h}(\mathrm{~A}-\mathrm{D})$. (A) The effect of SM934 on cell viability was examined by CCK 8 assays. The secretion of IL-1 $\beta$ (B), IL-6 (C) and TNF- $\alpha$ (D) were detected by ELISA in the supernatant of cell culture. (E) The protein level of p-NF-kB (phosphorylated p65) was determined by Western blot, and the representative data were shown. (F) Effect of SM934 on nuclear translocation of p-NF-kB. Cells were stained with DAPI (blue) and anti-phosphorylated p65 (red). Data are presented as mean \pm SEM of three independent experiments. ${ }^{*} P<0.05,{ }^{* *} P<0.01$ vs LPS group.

immune system, such as $\mathrm{T}$ and $\mathrm{B}$ cell activation and antibody production. However, the impact of SM934 on the innate immune system remains largely unclear.

In the present study, SM934 was orally administered following DSS-induced acute colitis mainly driven by the innate immune system ${ }^{[4]}$ to evaluate its protective effects on the intestinal tract. Our results showed that SM934 significantly alleviates the acute intestinal injury induced by DSS administration, including body weight loss, DAI scores, colon length shorting, and fecal occult blood. MPO activity is a marker of neutrophil infiltration and is proportional to the number of neutrophils in the inflamed tissue ${ }^{[34]}$. In our study, a significant reduction of MPO activity was found after SM934 treatment compared with the vehicle control. Using flow cytometry analysis, we further revealed that the percentages of macrophages and neutrophils in spleens and MLNs were significantly reduced by SM934 treatment. These results suggest that the protective effects of SM934 on DSS-induced colonic damage were related to the inhibition of infiltration of macrophages and neutrophils in spleens and MLNs.

It has been demonstrated that increased levels of proinflammatory mediators including inflammatory cytokines IL-1 $\beta$, IL-6, TNF- $\alpha$ and chemokines such as MIP-1a, play a crucial role in the pathogenesis of DSS-induced ulcerative colitis and correlate with the severity of inflammation ${ }^{[2]}$. These pro-inflammatory factor levels in colon tissue were also highly elevated in response to invading bacteria and their products in IBD patients ${ }^{[35]}$. Using quantitative qRT-
PCR and ELISA assays, we found that SM934 significantly inhibited both mRNA and protein expression of IL-1 $\beta$, IL-6 TNF- $\alpha$, and MIP-1a in the colon tissues compared with the levels in the DSS group. The inducible isoform of nitric oxide synthase (iNOS) has been shown to play an important role in modulating the expression of pro- and anti-inflammatory genes $^{[36]}$. Inhibition of tissue iNOS expression has been shown to alleviate inflammation in UC. Our results demonstrated that SM934 treatment significantly inhibited iNOS expression in the colon tissues. Furthermore, we revealed that SM934 administration markedly reversed the increased macrophage and neutrophil infiltration in colon tissues in DSS-induced colitis mice as evaluated by flow cytometry analysis. Taken together, these data further demonstrate that SM934 reduced the increased infiltration of macrophages and neutrophils in colon tissues, leading to the reduced expression of colonic proinflammatory mediators and iNOS.

NF-kB and/or MAPKs are signal messengers that regulate pro-inflammatory gene transcription in the inflammatory process $^{[37]}$. NF- $\mathrm{kB}$ exists in the cytoplasm as an inactive form, and its activation is tightly regulated by $\mathrm{I}-\mathrm{k} B$, which undergoes phosphorylation and degradation followed by NF-кB nuclear translocation ${ }^{[27]}$. Nuclear translocation of NF-kB activates its target genes to promote the expression of various pro-inflammatory cytokines and mediators. Previous studies have shown that NF-kB inhibitors suppress pro-inflammatory cytokine production and ameliorate experimental colitis ${ }^{[34]}$. As evaluated by IF and Western blot analyses in this study, 
DSS induction of colitis resulted in rapid phosphorylation and degradation of I-kB in colonic mucosa. In contrast, SM934 suppressed DSS-induced phosphorylation of I-kB and nuclear translocation of NF-kB in colonic mucosa. Moreover, an obvious reduction of phosphorylation of MAPK extra-cellular signal-regulated kinase (ERK1/2) was observed following SM934 treatment. These results in vivo indicate that SM934 has a role in the suppression of DSS colitis-induced NF- $\mathrm{KB}$ activation. Therefore, SM934 might attenuate DSS-induced colitis inhibiting NF-KB activation and ERK cell signaling.

To validate the conclusion from our in vivo study, we further evaluated the protective effects of SM934 in vitro using LPS-stimulated RAW 264.7 and THP-1 cells. Our results demonstrated that the secretion of pro-inflammatory cytokines in the two kinds of macrophage-like cells was inhibited after SM934 treatment. In addition, SM934 administration significantly inhibited the secretion of $\mathrm{NO}$ and expression of iNOS in LPS-stimulated RAW 264.7 cells and inhibited nuclear translocation of NF-кB in THP-1 cells. These data further revealed that SM934 suppressed the transcription and final secretion of pro-inflammatory factors through the inhibition of the NF- $\mathrm{kB}$ signaling pathway.

In conclusion, our study explored a novel therapeutic strategy for ulcerative colitis by targeting the innate immune system with a novel water soluble artemisinin analogue, SM934. We found that SM934 could ameliorate DSSinduced acute colitis mainly by suppressing macrophages and neutrophils and inhibiting activation of the NF-kB cell signaling pathway. Our results suggest that SM934 might serve as a potential alternative candidate for the treatment of UC. However, more animal models, such as DSS-induced chronic colitis, TNBS-induced colitis and T cell transfer colitis, are needed to assess the pharmacodynamics of SM934 in the treatment of IBD.

\section{Acknowledgements}

This work was supported by grants "Personalized MedicinesMolecular Signature-based Drug Discovery and Development", Strategic Priority Research Program of the Chinese Academy of Sciences (Grant № XDA12020107), National Science \& Technology Major Project “New Drug Creation and Manufacturing Program", China (№ 2017ZX09101002-002-010), National Natural Science Foundation of China (NSFC, 81673445). And we are grateful to Dr Lin WANG (University of Michigan) who kindly contributed to the manuscript revision.

\section{Author contribution}

Jian-ping ZUO, Wei TANG, Yu-xi YAN and Shi-jun HE conceived and designed the experiments. Yu-xi YAN, Mei-juan SHAO, Xiao-qian YANG, Yan-sheng XU, Qing QI, Feng-hua ZHU, Pei-lan HE and Chun-lan FENG performed the experiments. Jian-ping ZUO, Yu-xi YAN and Wei TANG analyzed the data. Jian-ping ZUO, Yu-xi YAN and Wei TANG contributed reagents/materials/analysis tools. Jian-ping ZUO, Yu-xi YAN and Wei TANG wrote the paper. Wei TANG, Yan-wei WU and Heng LI contributed to the manuscript revision.

\section{References}

1 Podolsky DK. Inflammatory bowel disease. N Engl J Med 2002; 347: 417-29.

2 Xavier RJ, Podolsky DK. Unravelling the pathogenesis of inflammatory bowel disease. Nature 2007; 448: 427-34.

3 Wirtz S, Neurath MF. Mouse models of inflammatory bowel disease. Adv Drug Deliv Rev 2007; 59: 1073-83.

4 Grimm MC, Pullman WE, Bennett GM, Sullivan PJ, Pavli P, Doe WF. Direct evidence of monocyte recruitment to inflammatory bowel disease mucosa. J Gastroenterol Hepatol 1995; 10: 387-95.

5 Neurath MF. Cytokines in inflammatory bowel disease. Nat Rev Immunol 2014; 14: 329-42.

6 Mahida YR. The key role of macrophages in the immunopathogenesis of inflammatory bowel disease. Inflamm Bowel Dis 2000; 6: 21-33.

7 Schottelius AJ, Dinter H. Cytokines, NF-kappaB, microenvironment, intestinal inflammation and cancer. Cancer Treat Res 2006; 130: 67-87.

8 Rogler G, Brand K, Vogl D, Page S, Hofmeister R, Andus T, et al. Nuclear factor kappaB is activated in macrophages and epithelial cells of inflamed intestinal mucosa. Gastroenterology 1998; 115: 357-69.

9 Neurath MF, Fuss I, Schurmann G, Pettersson S, Arnold K, MullerLobeck $\mathrm{H}$, et al. Cytokine gene transcription by NF-kappa B family members in patients with inflammatory bowel disease. Ann N Y Acad Sci 1998; 859: 149-59.

10 Neurath MF, Pettersson S, Meyer zum Buschenfelde KH, Strober W. Local administration of antisense phosphorothioate oligonucleotides to the p65 subunit of NF-kappa B abrogates established experimental colitis in mice. Nat Med 1996; 2: 998-1004.

11 Li TT, Zhang XH, Jing JF, Li X, Yang XQ, Zhu FH, et al. Artemisinin analogue SM934 ameliorates the proteinuria and renal fibrosis in rat experimental membranous nephropathy. Acta Pharmacol Sin 2015; 36: 188-99.

12 Li X, Li TT, Zhang XH, Hou LF, Yang XQ, Zhu FH, et al. Artemisinin analogue SM934 ameliorates murine experimental autoimmune encephalomyelitis through enhancing the expansion and functions of regulatory T cell. PLoS One 2013; 8: e74108.

13 Lin ZM, Yang XQ, Zhu FH, He SJ, Tang W, Zuo JP. Artemisinin analogue SM934 attenuate collagen-induced arthritis by suppressing $T$ follicular helper cells and T helper 17 cells. Sci Rep 2016; 6: 38115.

14 Hou LF, He SJ, Li X, Yang Y, He PL, Zhou Y, et al. Oral administration of artemisinin analog SM934 ameliorates lupus syndromes in MRL/ Ipr mice by inhibiting Th1 and Th17 cell responses. Arthritis Rheum 2011; 63: 2445-55.

15 Wu Y, He S, Bai B, Zhang L, Xue L, Lin Z, et al. Therapeutic effects of the artemisinin analog SM934 on lupus-prone MRL/Ipr mice via inhibition of TLR-triggered B-cell activation and plasma cell formation. Cell Mol Immunol 2016; 13: 379-90.

16 Grahames CB, Michel AD, Chessell IP, Humphrey PP. Pharmacological characterization of ATP- and LPS-induced IL-1beta release in human monocytes. Br J Pharmacol 1999; 127: 1915-21.

17 Chassaing B, Aitken JD, Malleshappa M, Vijay-Kumar M. Dextran sulfate sodium (DSS)-induced colitis in mice. Curr Protoc Immunol 2014; 104: Unit 1525.

18 Zhang L, Zhang Y, Zhong W, Di C, Lin X, Xia Z. Heme oxygenase-1 ameliorates dextran sulfate sodium-induced acute murine colitis by regulating Th17/Treg cell balance. J Biol Chem 2014; 289: 26847 58.

19 Kane S, Marchioni Beery R. Current approaches to the management of new-onset ulcerative colitis. Clin Exp Gastroenterol 2014; 7: 11132.

20 Santucci L, Fiorucci S, Rubinstein N, Mencarelli A, Palazzetti B, 
Federici B, et al. Galectin-1 suppresses experimental colitis in mice. Gastroenterology 2003; 124: 1381-94.

$21 \mathrm{Kim} \mathrm{JJ,} \mathrm{Shajib} \mathrm{MS,} \mathrm{Manocha} \mathrm{MM,} \mathrm{Khan} \mathrm{WI.} \mathrm{Investigating} \mathrm{intestinal}$ inflammation in DSS-induced model of IBD. J Vis Exp 2012; (60). pii: 3678. doi: 10.3791/3678.

22 Lefrancois L, Lycke N. Isolation of mouse small intestinal intraepithelial lymphocytes, Peyer's patch, and lamina propria cells. Curr Protoc Immunol 2001; Chapter 3: Unit 3.19.

23 Qi Q, Li H, Lin ZM, Yang XQ, Zhu FH, Liu YT, et al. (5R)-5hydroxytriptolide ameliorates anti-glomerular basement membrane glomerulonephritis in NZW mice by regulating Fcgamma receptor signaling. Acta Pharmacol Sin 2018; 39: 107-16.

24 Wang JX, Hou LF, Yang Y, Tang W, Li Y, Zuo JP. SM905, an artemisinin derivative, inhibited NO and pro-inflammatory cytokine production by suppressing MAPK and NF-kappaB pathways in RAW 264.7 macrophages. Acta Pharmacol Sin 2009; 30: 1428-35.

25 Yan Y, Kolachala V, Dalmasso G, Nguyen H, Laroui H, Sitaraman SV, et al. Temporal and spatial analysis of clinical and molecular parameters in dextran sodium sulfate induced colitis. PLoS One 2009; 4: e6073.

26 Serra AM, Waddell J, Manivannan A, Xu H, Cotter M, Forrester JV. $\mathrm{CD} 11 \mathrm{~b}^{+}$bone marrow-derived monocytes are the major leukocyte subset responsible for retinal capillary leukostasis in experimental diabetes in mouse and express high levels of CCR5 in the circulation. Am J Pathol 2012; 181: 719-27.

27 Atreya I, Atreya R, Neurath MF. NF-kappaB in inflammatory bowe disease. J Intern Med 2008; 263: 591-6.

28 Bauer C, Duewell P, Mayer C, Lehr HA, Fitzgerald KA, Dauer M, et al. Colitis induced in mice with dextran sulfate sodium (DSS) is mediated by the NLRP3 inflammasome. Gut 2010; 59: 1192-9.

29 Ananthakrishnan AN. Epidemiology and risk factors for IBD. Nat Rev Gastroenterol Hepatol 2015; 12: 205-17.

30 Dieleman LA, Ridwan BU, Tennyson GS, Beagley KW, Bucy RP, Elson CO. Dextran sulfate sodium-induced colitis occurs in severe combined immunodeficient mice. Gastroenterology 1994; 107: 1643-52.

31 Geremia A, Biancheri P, Allan P, Corazza GR, Di Sabatino A. Innate and adaptive immunity in inflammatory bowel disease. Autoimmun Rev 2014; 13: 3-10.

$32 \mathrm{Li} \mathrm{H,} \mathrm{Zuo} \mathrm{J,} \mathrm{Tang} \mathrm{W.} \mathrm{Water-soluble} \mathrm{artemisinin} \mathrm{derivatives} \mathrm{as}$ promising therapeutic immunosuppressants of autoimmune diseases. Cell Mol Immunol 2017 Sep 11. doi: 10.1038/cmi.2017.87.

33 Hou LF, He SJ, Li X, Yang Y, He PL, Zhou Y, et al. Oral administration of artemisinin analog SM934 ameliorates lupus syndromes in MRL/ Ipr mice by inhibiting Th1 and Th17 cell responses. Arthritis Rheum 2011; 63: 2445-55.

34 Wei W, Ding M, Zhou K, Xie H, Zhang M, Zhang C. Protective effects of wedelolactone on dextran sodium sulfate induced murine colitis partly through inhibiting the NLRP3 inflammasome activation via AMPK signaling. Biomed Pharmacother 2017; 94: 27-36.

35 Cerf-Bensussan N, Gaboriau-Routhiau V. The immune system and the gut microbiota: friends or foes? Nat Rev Immunol 2010; 10: 735-44.

36 Ajuebor MN, Virag L, Flower RJ, Perretti M, Szabo C. Role of inducible nitric oxide synthase in the regulation of neutrophil migration in zymosan-induced inflammation. Immunology 1998; 95: 625-30.

37 Zhang DK, Cheng LN, Huang XL, Shi W, Xiang JY, Gan HT. Tetrandrine ameliorates dextran-sulfate-sodium-induced colitis in mice through inhibition of nuclear factor-kappaB activation. Int J Colorectal Dis 2009; 24: 5-12. 